\title{
Burkholderia pseudomallei infection in a patient with diabetes presenting with multiple splenic abscesses and abscess in the foot: a
}

\author{
case report \\ Rahul Dhodapkar, S Sujatha*, K Sivasangeetha, G Prasanth and \\ Subhash Chandra Parija
}

Address: Department of Microbiology, Jawaharlal Institute of Postgraduate Medical Education and Research, Pondicherry, PIN 605006, India Email: Rahul Dhodapkar - rahuldhodapkar@gmail.com; S Sujatha* - sujathasistla@gmail.com; K Sivasangeetha - sujathasistla@gmail.com; G Prasanth - sujathasistla@gmail.com; Subhash Chandra Parija - parijasc@yahoo.com

* Corresponding author

Published: 7 October 2008

Cases Journal 2008, 1:224 doi:10.1 186/1757-1626-I-224

This article is available from: http://www.casesjournal.com/content/I/I/224

(C) 2008 Dhodapkar et al; licensee BioMed Central Ltd.

This is an Open Access article distributed under the terms of the Creative Commons Attribution License (http://creativecommons.org/licenses/by/2.0), which permits unrestricted use, distribution, and reproduction in any medium, provided the original work is properly cited.
Received: 26 June 2008

Accepted: 7 October 2008

\begin{abstract}
Introduction : Melioidosis or infection with Burkholderia pseudomallei presents with protean manifestations. We present a case of melioidosis in a diabetic patient from India. The case is presented to highlight the importance of early microbiologic diagnosis and subsequent institution of appropriate therapy to achieve a better prognosis

Case presentation: A male bachelor around 50 years of age from India presented with low grade fever, bilateral ankle swelling and hypochondrial pain. On examination patient had diabetes and had multiple abscesses in bilateral ankle, knee and splenic region. Microbiologic diagnosis revealed the etiologic agent to be Burkholderia pseudomallei. Patient was managed with iv ceftazidime and surgical excision.

Conclusion: The case report highlights the importance of early identification of etiologic agent. $B$. pseudomallei identification requires a great deal of clinical suspicion as well as alertness on the part of the medical microbiologist as these isolates are often reported as Pseudomonas spp. Correct identification of the etiologic agent is essential as $B$ pseudomallei requires prolonged antimicrobial therapy for a better clinical outcome.
\end{abstract}

\section{Introduction}

Melioidosis is a systemic infection caused by non fermenting gram negative bacilli Burkholderia pseudomallei. It is endemic in South East Asia and Australia[1] where it causes infections with protean manifestations. It is now recognized as an emerging infectious disease in India [2]. We present a case report of $B$. pseudomallei infection in a diabetic presenting with multiple splenic abscesses and abscess in foot.

\section{Case presentation}

A male bachelor aged 50 years presented with low grade fever for duration of one month, bilateral ankle swelling and left hypochondrial pain for duration of 15 days with associated symptoms of anorexia, nausea and weight loss. There was no history of travel to any foreign country. He was an agricultural worker by profession.

On examination bilateral swelling in ankle region with tenderness, with restriction in movement of affected joint 
was observed(Figure 1); per abdomen examination revealed a spleen of $4 \mathrm{~cm}$ below the costal margin which was tender on palpation. USG abdomen confirmed the physical finding of an enlarged spleen with multiple hypo echoic lesions, largest being $3 \mathrm{~cm}$ in diameter. $\mathrm{X}$ ray of ankles was normal with no joint involvement. Ultrasonographic examination revealed a collection of fluid in subcutaneous plane in bilateral ankle region(Figure 2). Investigations revealed neutrophilia, raised ESR and a markedly elevated ALP- $750 \mathrm{U} / \mathrm{L}$. The patient was diagnosed to be a diabetic on the basis of oral glucose tolerance test. Further during the course of his stay in the hospital, the patient developed a swelling in his right knee. At this point a differential diagnosis of tuberculosis, AIDS with multiple site infections, and infective endocarditis were considered. However these were ruled out as specific tests for tuberculosis and HIV were negative, blood culture was negative and there were no cardiac abnormalities detected in the echocardiogram. A diagnostic aspirate from the left ankle revealed frank pus which on gram staining revealed the presence of gram negative bacilli with a typical safety pin appearance. Culture from the pus grew dry wrinkled colonies on blood agar and pinkish rugose colonies on MacConkey's agar(Figure 3). The peculiar appearance on gram staining and colony characters on culture raised the suspicion of $B$. pseudomal$l e i$. The isolate was identified as B. pseudomallei by standard biochemical methods [3] and was found to be sensitive to ciprofloxacin and ceftazidime. The patient was started on Ceftazidime 2 grams iv given 8 hourly, abscesses were drained surgically, repeat cultures were positive for two weeks but were sterile thereafter; iv antibiotics were continued for one month. Control of the patient's blood sugar was achieved simultaneously and he was discharged after a month. One of the surprising fea-

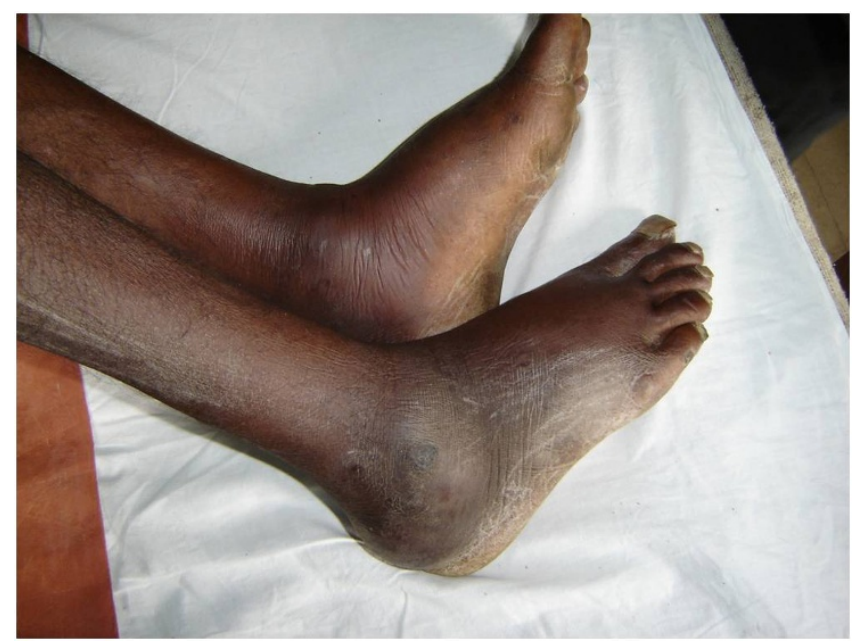

Figure I

Bilateral ankle swelling.

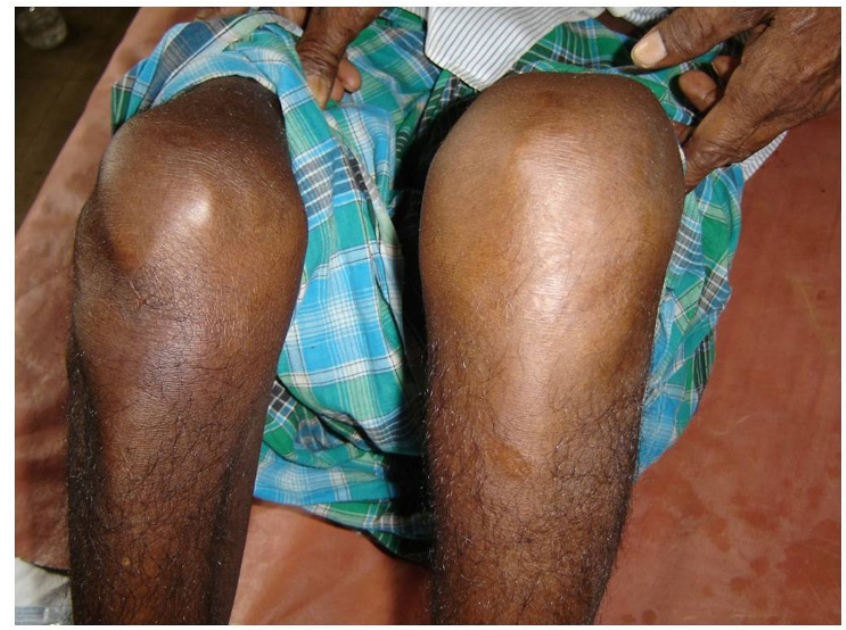

Figure 2

Left knee swelling.

tures was that the patient remained afebrile throughout the course of hospitalization.

\section{Discussion}

Burkholderia pseudomallei is a soil saprophyte, endemic in south east Asian countries - Vietnam, Thailand and also in Australia[1]. Though inoculation is believed to be the major mode of infection, ingestion and person to person transmission have also been suggested in certain cases. $B$.

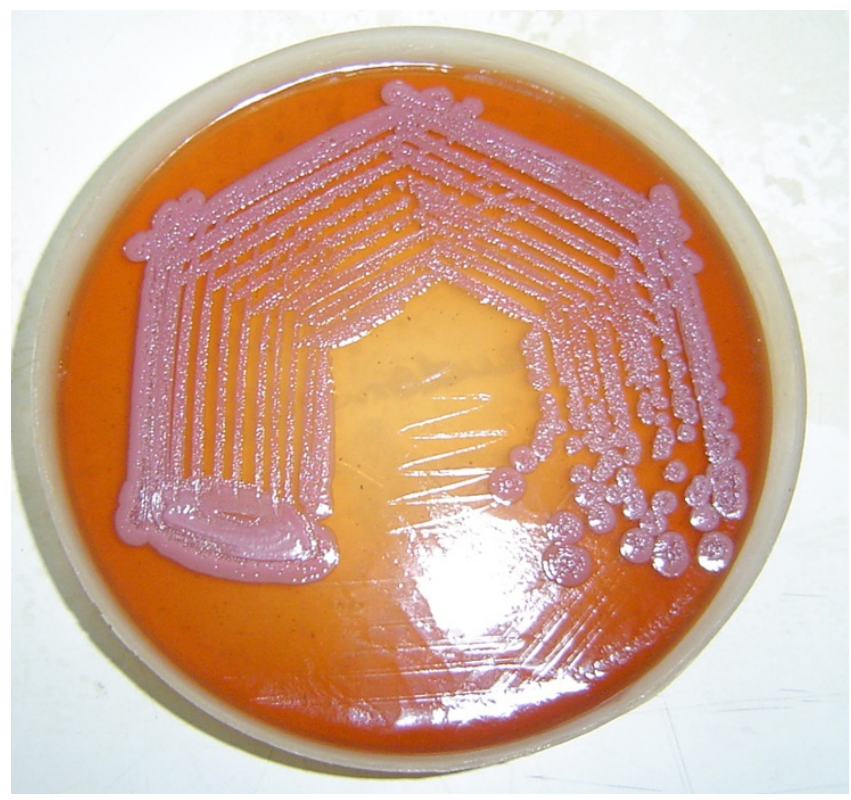

Figure 3

Growth of Burkholderia pseudomallei on Mac Conkey agar showing pink, rugose colonies with a metallic sheen. 
pseudomallei infections are known for their protean manifestations ranging from systemic manifestations like septicemia, pneumonia \& multiple abscesses to asymptomatic infections, local ulcers and abscesses without systemic manifestations. Recently there have been increasing reports of infections with $B$. pseudomallei from India. Cases reported from Indian subcontinent varied from serious manifestations like septicaemia [4,5], septic arthritis[6,7], pneumonia[7] to soft tissue infections like scalp abscess, psoas abscess, gluteal abscess [7]etc.

The patient in question presented with multiple splenic abscesses, abscesses in his feet and went on to develop swelling in his right knee. He was later diagnosed to be a diabetic during his stay in the hospital. Diabetes has been found to be the single most common predisposing factor in a review [8]. No case reports describing sequential swellings in the feet followed by knees were found after a search of existing literature, though progression of cutaneous swellings to necrotizing fascitis has been described [9]. Though the patient had multiple foci of infection he presented with remarkably mild symptoms and there were no complications associated with the management.

\section{Conclusion}

Melioidosis as a differential diagnosis should be an option in multiple abscesses especially in patients with predisposing factors in the Indian subcontinent as there has been an upsurge in case reports of $B$. pseudomallei infections from the region. A very high index of suspicion should be kept both clinically and at laboratory level as cultures of $B$. pseudomallei can very easily be misidentified as those of Pseudomonas. Atypical presentations in non endemic areas in patients with predisposing conditions with inconclusive routine investigation should prompt the clinician to ask for a travel history to any of the areas where the organism is endemic or sporadic. The situation can be further complicated by the reactivation of a latent focus of infection acquired many years ago as has been seen in American soldiers returned from the Vietnam War $[10,11]$. Correct identification of B. pseudomallei is essential as treatment of these infections require intensive and prolonged treatment $[12,13]$.

\section{Abbreviations}

USG: Ultrasonography; ESR: Erythrocyte sedimentation rates; ALP: Alkaline phosphatase; AIDS: Acquired immunodeficiency disease; HIV: Human immunodeficiency virus.

\section{Consent}

Written informed consent was obtained from the patient for publication of this case report and accompanying images. A copy of the written consent is available for review by the Editor-in-Chief of this journal.

\section{Competing interests}

The authors declare that they have no competing interests.

\section{Authors' contributions}

RD contributed in preparation of manuscript, SS \& KS isolated and characterized the isolate, PG was the physician incharge for the patient, SCP contributed in editing the manuscript. All authors read and approved the final manuscript.

\section{References}

I. White NJ: Melioidosis. Lancet 36 I(9370): 17|5-22. 2003 May 17;

2. John TJ, Jesudason MV, Lalitha MK, Ganesh A, Mohandas V, Cherian T, Mathai D, Chandy MJ: Melioidosis In India: the tip of the iceberg? Indian J Med Res 1996, 103:62-5.

3. Gilligan PH, Susan W: Burkholderia, Stenotrophomonas, Ralstonia, Brevudomonas, Commamonas, Acidovorax. In Manual of Clinical Microbiology Volume Chapter 34. 7th edition. Edited by: Murray PS, Baron ES, Pfaller MA, Tenover FC, Yolken RH. ASM Press: Washington DC; 1999:526.

4. Jesudason MV, Anbarasu A, John TJ: Septicaemic melioidosis in a tertiary care hospital in south India. Indian J Med Res 2003, II7:119-2I.

5. Anuradha K, Meena AK, Lakshmi V: Isolation of Burkholderia pseudomallei from a case of septicaemia - A case report. Indian J Med Microbiol 2003, 2 I(2): I29-132.

6. Danda D, Thomas K: Transient asceptic arthritis of knees in a patient with melioidosis. Indian J Med Sci 2000, 54(I): 18-20.

7. Vidyalakshmi K, Shrikala B, Bharathi B, Suchitra U: Melioidosis: an under-diagnosed entity in western coastal India: a clinicomicrobiological analysis. Indian J Med Microbiol 2007, 25(3):245-8.

8. Melioidosis: Epidemiology, Pathophysiology, and Management. Clinical Microbiology Reviews 2005:383-416.

9. Wang YS, Wong $\mathrm{CH}$, Kurup A: Cutaneous melioidosis and necrotizing fasciitis caused by Burkholderia pseudomallei. Emerg Infect Dis 2003, 9: I 484- I 485.

10. Mackowiak PA, Smith JW: Septicemic melioidosis. Occurrence following acute influenza six years after exposure in Vietnam. JAMA 1978, 240:764-766.

II. Chodimella U, Hoppes WL, Whalen S, Ognibene AJ, Rutecki GW: Septicemia and suppuration in a Vietnam veteran. Hosp Pract (Minneap) 1997, 32(5):219-22I.

12. White NJ, Dance DA, Chaowagul W, Wattanagoon Y, Wuthiekanun V, Pitakwatchara N: Halving of mortality of severe melioidosis by ceftazidime. Lancet 1989, ii:697-70I.

13. Sookpranee M, Boonma P, Susaengrat W, Bhuripanyo K, Punyagupta $\mathrm{S}$ : Multicenter prospective randomized trial comparing ceftazidime plus corimoxazole with chloramphenicol plus doxycycline and cotrimoxazole for treatment of severe melioidosis. Antimicrob Agents Chemother 1992, 36:158-162.

Publish with Bio Med Central and every scientist can read your work free of charge

"BioMed Central will be the most significant development for disseminating the results of biomedical research in our lifetime."

Sir Paul Nurse, Cancer Research UK

Your research papers will be:

- available free of charge to the entire biomedical community

- peer reviewed and published immediately upon acceptance

- cited in PubMed and archived on PubMed Central

- yours - you keep the copyright

Submit your manuscript here:

http://www.biomedcentral.com/info/publishing_adv.asp

BiolMedcentral 